\title{
Drylab 2023: living a possible future with resource scarcity
}

\author{
$\underline{\text { Marco A. Janssen }}^{1}, \underline{\text { Adriene Jenik }}^{2}, \underline{\text { Sarra Z. Tekola }}^{1}, \underline{\text { Krista L. Davis }}^{2}, \underline{\text { Shalae Flores }}^{3}, \underline{\text { Willa Gibbs }}^{4}, \underline{\text { Molly Koehn }}^{2}$, Valerie Lyons $^{2}$,
} Cydnei Mallory $^{2},{ }_{\text {Sydney Rood }}^{1,5}$, Séverin Guelpa $^{6}{ }^{2}{ }^{2}$ Luz-Andrea Pfister $^{7}$

\begin{abstract}
We report on an art and sustainability project, inspired by sustainable living and by the work of Elinor Ostrom, in which the authors experienced a not-too-distant future of water scarcity in an isolated location in the Mojave Desert for four weeks. We restricted our water use to $\leq 15.1 \mathrm{~L} /$ day (4 gallons) water per person and consumed a water-wise vegan diet. Here, we report and reflect on our experience of this art and sustainability project. We show that, as participants, we had no difficulty adjusting to a resourcescarce environment or living in a remote location. Our experience showed that (temporary) behavioral change is possible to cope with extreme resource scarcity without a net negative effect on the quality of life. Future replications of such art and sustainability projects in safer environments could become spaces for science, art, and innovation for more sustainable lifestyles.
\end{abstract}

Key Words: art and sustainability; collective action; commons; governance; water; water scarcity

\section{INTRODUCTION}

The typical U.S. resident lives far beyond the means of Earth's carrying capacity. The combination of population increase, increasing wealth, smaller households, improved sanitation, more meat-heavy diets, irrigated agriculture, and other lifestyle changes (Vörösmarty et al. 2000, Hoekstra and Chapagain 2007) has led to increased water use and the depletion of groundwater aquifers around the world (Konikow and Kendy 2005). The depletion of groundwater is largely invisible from the Earth's surface. As a result, humankind has not responded in a timely manner to the depletion of this resource, and groundwater extraction continues to increase every decade (Konikow 2013). Climate change is expected to amplify the water crisis through long-term droughts akin to what was experienced recently in the southwestern regions of the United States (Elliot et al. 2014, Cook et al. 2015).

Within the United States, daily water use averages 300-380 L/ person (U.S. Geological Survey, https://water.usgs.gov/edu/qahome-percapita.html). Expected droughts and the depletion of groundwater aquifers will compel the creation of additional infrastructure to bring fresh water to urban areas. This will increase the cost of water delivery. Even without these extra infrastructure demands, Mack and Wrase (2017) estimate that by 2020, one in three U.S. households will have difficulty paying their water bill should current water consumption rates continue. The rising cost of water in Mack and Wrase's (2017) study is largely caused by an aging water infrastructure that requires huge investments to maintain operations. In many cases, infrastructure needs have led municipalities to privatize control of their water systems, a trend seen globally in recent decades (Bakker 2010).

How much water do we actually need? The World Health Organization recommends a minimum of $7.5 \mathrm{~L} /$ person per day for basic water needs, and $20 \mathrm{~L} /$ person per day if we take care of basic hygiene needs and basic food hygiene (http://www.who.int/ water sanitation health/emergencies/qa/emergencies qa5/en/). Gleick (1996) recommends $50 \mathrm{~L} /$ person per day to meet basic human needs. These $50 \mathrm{~L}$ include $5 \mathrm{~L}$ of drinking water, $10 \mathrm{~L}$ for cooking and food preparation, $15 \mathrm{~L}$ for bathing, and $20 \mathrm{~L}$ for sanitation.

What does it mean to live on a low water budget? Here, we reflect on our experiences with Drylab 2023, an art and sustainability project based on sustainability concepts in which eight participants lived for one month in a remote area of the Mojave Desert in California, USA, enacting a potential future of extreme water scarcity (http://drylab2023.net/). We were allowed to use 15.1 L/day (4 U.S. gallons) of water and had to coordinate with each other in the use of our limited resources.

To put this in context, the 2018 water crisis in Cape Town, South Africa, forced residents to reduce their water consumption by $50 \%$ over a period of three years (City of Cape Town 2018). In contrast, we reduced our water consumption by $95 \%$ overnight for a fourweek period.

Drylab 2023, as an art and sustainability project, was a collaboration between a sustainability scientist (Janssen) and an artist (Jenik). It was initiated to create a scenario in which a group would have to craft and adjust institutional arrangements to govern their shared resources (Ostrom 1990). The work of Elinor Ostrom and her colleagues has demonstrated, using case study analysis and controlled experiments, that groups are able to organize in ways that overcome the tragedy of the commons and are thus able to manage their shared resources sustainably (Ostrom 2010, Poteete et al. 2010). Communities are more likely to find collaborative solutions if they meet Ostrom's (2010) design principles such as the right to organize, existence of clearly defined boundaries of the shared resources, monitoring and enforcement, and conflict resolution mechanisms.

As an art and sustainability project, we were able to explore a more extreme situation than could be explored in a scientifically controlled experiment. In fact, the project allowed us to observe the evolution of institutional arrangements. Because this is an art and sustainability project, and not a formal scientific experiment,

${ }^{1}$ School of Sustainability, Arizona State University, USA, ${ }^{2}$ School of Art, Arizona State University, USA, ${ }^{3}$ School of Geographical Sciences and Urban Planning, Arizona State University, USA, ${ }^{4}$ Arizona State University, USA, ${ }^{5}$ School of Community Resources and Development, Arizona State University, USA, ${ }^{6}$ MATZA, Geneva, Switzerland, ${ }^{7}$ Pfister Lab Web Development, Fountain Hills, USA 
we cannot claim that our experiences can be generalized. However, as Scheffer et al. (2015) argue, a collaboration between scientists and artists may create novel reflections because artists unlock associative reasoning and intuition, whereas scientists may focus on deliberate reasoning. Although we are not testing formal scientific hypothesis, this kind of collaboration may generate some novel reflections, at least for the participants. In addition to its framing as an art and sustainability project performed by science and art students, Drylab 2023 is an example of extreme experiential learning during which we engaged in open-ended discovery and full-bodied engagement with each other in a harsh environment.

Here, we provide the context of the art and sustainability project and its implementation. Furthermore, we describe what happened and reflect on the experience using Ostrom's (2010) design principles.

\section{CONTEXT OF THE PROJECT}

\section{Experiencing self-imposed constraints}

In Drylab 2023, a group of eight participants, both art and science students, and the first two authors volunteered to live together for four weeks in a remote location in the Mojave desert, California, USA, with a restricted amount of water per person per day. Living in self-imposed resource constraints is not a unique practice for artists. Throughout the 20 th and 21 st centuries, artists have used their bodies and time to reflect upon and explore new ways of being in the world.

We do not aim to provide a comprehensive review, but we point to some relevant historical precursors to Drylab 2023. These works include the series of endurance pieces undertaken by Tehching Hsieh such as Rope Piece (1983-1984) in which Hsieh was tied to artist Linda Montano by a $2.4-\mathrm{m}$ ( 8 foot) rope for one year, and Cage Piece (1978-1979) in which Hsieh lived in a small cell-like structure for one year (https://www.tehchinghsieh.com/ artworks). Another earlier example is Eleanor Antin's conceptual photography piece Carving: A Traditional Sculpture (1972; http:// www.artic.edu/aic/collections/artwork/144356) in which the artist spent 45 days on a strict dieting regimen and photographed herself each day from several angles, displaying the "sculpted" results.

In the Acali project by Mexican anthropologist Santiago Genovés, 11 people from diverse backgrounds were brought together in the summer of 1973 for 101 days to drift across the Atlantic on a small raft named Acali (Genovés 1975). Recent works that connect with Drylab's sustainability focus include Andrea Zittel's installation $A-Z$ Pocket Property (1999), a 44-ton floating concrete island anchored off the coast of Denmark, on which the artist lived for one month as an experiment in escapism and isolation (http://www.zittel.org/work/a-z-pocket-property); Marko Peljhan's Makrolab, an autonomous communications, research, and living-unit space capable of sustaining four people in conditions of isolation and insulation for up to 120 days (http:// v2.nl/archive/works/makrolab/); and the ambitious Biosphere 2 project located in Oracle, Arizona, USA. The latter project is largely understood as having emerged from a process of scientific inquiry and imagination but was originally envisioned and manifested by an experimental theater company, with scientists joining the project in its later stages of development (Smith 2010).
In Drylab 2023, we build on the tradition in art to pursue projects about experiences with self-imposed constraints. We incorporated into this tradition scholarship on collective action and the commons. Building on the work of Ostrom, we created a physical and fictional context in which we, as a group, would experience collective action problems in a possible future of water scarcity. As such, this is a novel type of art and sustainability project.

\section{Storyline}

Janssen and Jenik, as the faculty, created a fictional context in which eight of us, the participants, would report via social media from a future of water scarcity. The eight participants, who are students, were recruited through an open call sent to sustainability and art students at Arizona State University. The fact that the participants were all female was not part of the original intent, but was employed in the storyline for the project.

The story was set in 2023 in the southwestern United States. By 2023 , water scarcity has been triggered by another cycle of drought, increasingly contaminated water supplies because of reduced environmental protection as a consequence of the dismantling of the U.S. Environmental Protection Agency, and privatization of water resources instigated in response to needed infrastructure investments in California's water delivery system. Meanwhile, national human and financial resource needs to support ongoing war and defense commitments have outgrown the limits of an all-volunteer military, and those aged 18-34 are subject to military conscription. A "water privilege" database restricts water rights to those who have registered for or are performing military duty, are outside of the age range, are disabled, or are caring for young children. Our group of young, healthy, childless women have come together as a result of their "conscientious objector" status. Some have been shunned by their families because of their insistence on not serving the wars; some have voluntarily removed themselves so they do not drain their families' limited water resources.

Our storyline begins when the month starts. The women have continued to move further and further away from established cities to find a peaceful space to live. At the crossroads in Amboy, they meet Séverin, who is planning to move on from this spot. He offers to leave them the space and the remains of his water tank. In the first days, he orients them to the new space.

\section{Venue}

The Drylab 2023 project was implemented in the Dryland Motel of Matza Amboy (https://matza.net/tag/matza-amboy/). Matza is the general name of a series of artistic projects initiated by the Swiss artist Séverin Guelpa. Matza projects bring scientists and artists together in various extreme sites around the world to work together to express and explore how people interact with the environment.

Amboy is a privately owned, unincorporated community along historic Route 66 in California's Mojave Desert (Fig. 1). In the distant past, Amboy had a peak population of approximately 700 people. The economy was based on hosting travelers along Route 66 and a salt and borax extraction industry (for more information about the history and culture of the Mojave Desert see http:// mojaveproject.org/). With the opening of highway I-40 in 1973, use of Route 66 dropped precipitously, causing the demise of 
Amboy. Currently the town hosts a gas station as well as a postal office that serve the tourists who travel Route 66.

The Dryland Motel of Matza Amboy is located in the remains of a motel as well as in a dilapidated trailer on the property. There is no running water. Potable water needs to be imported from nearby towns, of which Twentynine Palms, at $80 \mathrm{~km}$ away, is the closest. As such, Amboy is an ideal setting for enacting a waterscarce future (Fig. 2).

Fig. 1. The venue where Drylab 2023 took place.

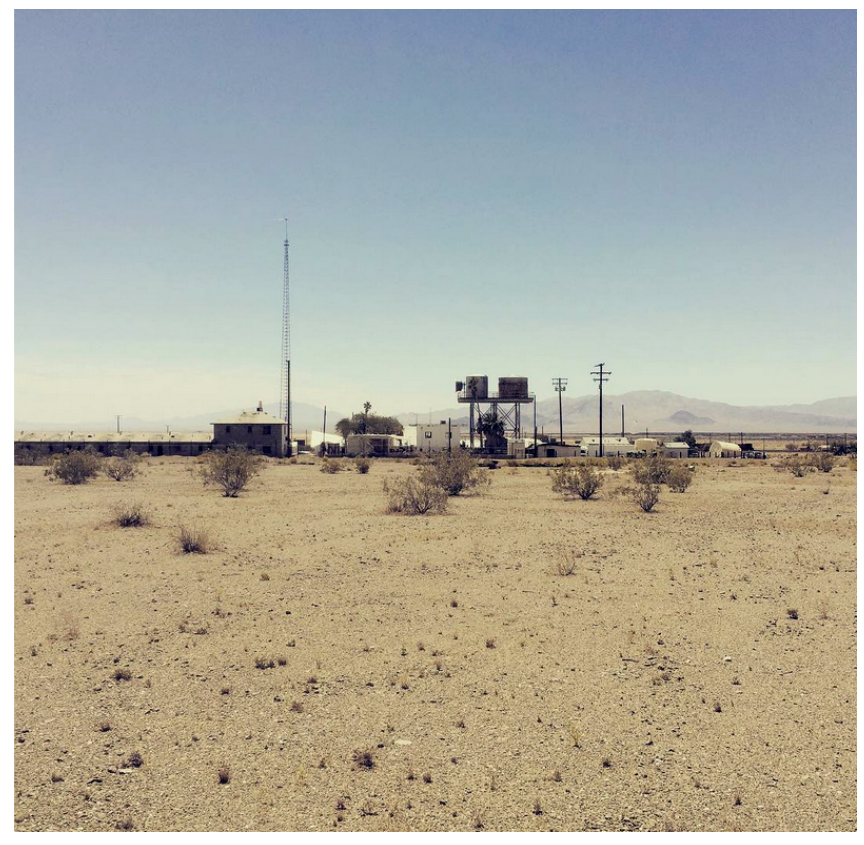

\section{Preparation before the project}

In the storyline we created for our project, we imagine a not-toodistant future in which fresh, clean water is scarce and expensive. We decided on a daily allocation of $15.1 \mathrm{~L} /$ day (4 gallons) of water, twice the recommended minimum of the World Health Organization. This would give us sufficient water to live in a desert climate with temperatures exceeding $40^{\circ} \mathrm{C}$ with limited air conditioning. In previous years, participants at Matza have used 8-11 L/day, but those participants also used the plentiful, nonpotable, salty water for sanitation and showers. In the Drylab 2023 experiment, all water came from the fresh water container, except for limited capture of salty water runoff, which was used by some participants to cool off in lieu of air conditioning.

In addition to the daily water constraint, we restricted what kinds of foods we could eat in a water scarce future. In the context of our storyline, we decided we would only consume food with a low water footprint that can be grown in the southwestern United States (Mekonnen and Hoekstra 2011). This meant no processed food, no meat, no dairy, no coffee, no chocolate, etc. A menu primarily consisting of squash, lettuce, kale, carrots, potatoes, tomatoes, southwest legumes, soybeans, masa, strawberries, dates, quinoa, and sunflower seeds supplied the food needs of the entire group.
We met a number of times as a group in the months before the experiment. Those of us who are students were exposed to the work of Elinor Ostrom and collective action problems related to water. We explored how concepts such as governance design principles could be applied to Drylab 2023. We also discussed food constraints and other logistical challenges. We crafted an initial set of rules on how we would pursue decision making during the experiment. The agreement was to work toward consensus where possible, and after that, to rely on majority vote. In addition, each of us would get one veto vote to halt a decision we were strongly against; no vetos were used during the project. During the experiment, faculty and staff observed the collective decision making on resource use and did not engage in the collective decision making.

The eight students received a budget for gas (USD \$200 for the month) and for food (USD \$10/day per person). Every three or four days, a few members of our group drove the $160 \mathrm{~km}$ roundtrip to the closest town, Twentynine Palms, to do grocery shopping. A water tank with $7600 \mathrm{~L}$ of water was purchased and was on site for the duration of the experiment.

The project took place from 13 May 2017 until 10 June 2017. The eight students were in Amboy for the full duration of the project, except for two who arrived on day five. Those of us who were faculty and staff stayed in Amboy in overlapping segments for the duration of the project and were not part of the storyline (except for Séverin Guelpa). However, we followed the same Drylab 2023 water and food restrictions as the participants while on site.

\section{WHAT HAPPENED}

During the project, we shared stories about our experiences via social media. The storyline facilitated the context of the social media presence of the project. Our identity and the location of the project were only revealed after the project was finished. The storyline served as the premise for all of our communication with the outside world during the project. All of the information, including a 12-min video compilation of the project, can be found at http://drylab2023.net/.

Here, we will discuss the way we governed our common resources. In the day-to-day practice in Amboy, we did not follow the roles in the storyline (which was mainly intended for the social media presence), except that those of us who are faculty and staff were observers and not participants of the collective decision making. Although the focus was on sharing common water scarcity, we developed a set of rules and norms covering a broad set of issues. In this synthesis, we focus on the main observations. Just prior to commencing the project, we were given general parameters guiding water allotment, food, and budget. Project directors offered a starting point of daily water distribution that included 7.55 L assigned individually and 7.55 L assigned to the commons. At the start of the stay in Amboy, however, we agreed on a change to a daily individual allotment of $11.35 \mathrm{~L}$ (drinking water, hygiene, washing clothes) and a 3.8-L contribution to common use (food preparation, washing dishes). Water for flushing the toilet would come from grey water collected from other uses of the pristine drinking water. Water collection was arranged a few times a day. Two of us were assigned as water stewards, charged with allocating the water from the tank into smaller individual and group 
Fig. 2. Map of the area around Amboy, California, USA. The nearest town with running water and services is Twentynine Palms (bottom left of map), which is $80 \mathrm{~km}$ from Amboy. Left of the map is the high and low temperature profile in Twentynine Palms (which is a few degrees cooler than in Amboy) during the project.

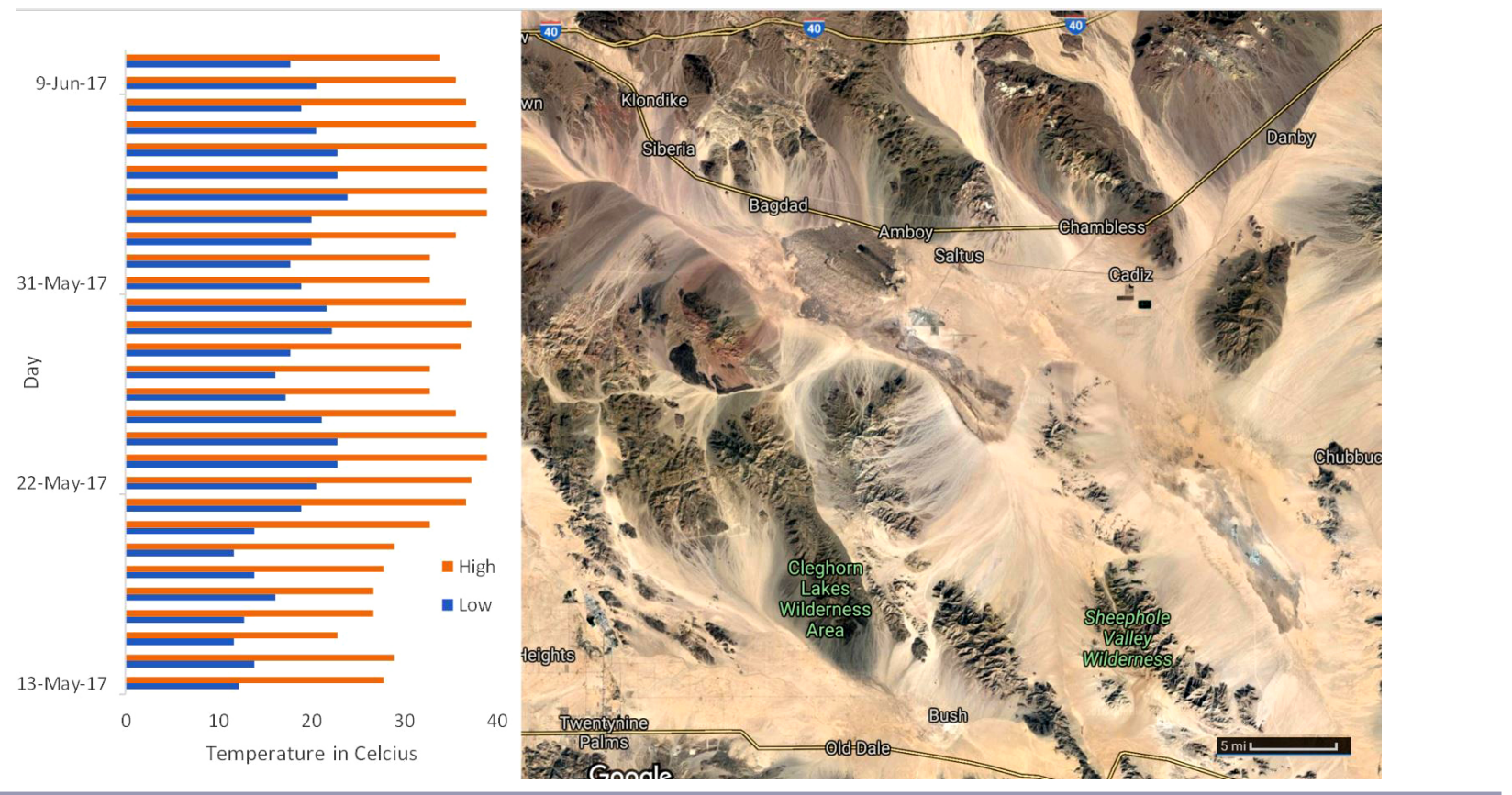

Fig. 3. Water distribution at the water tank.

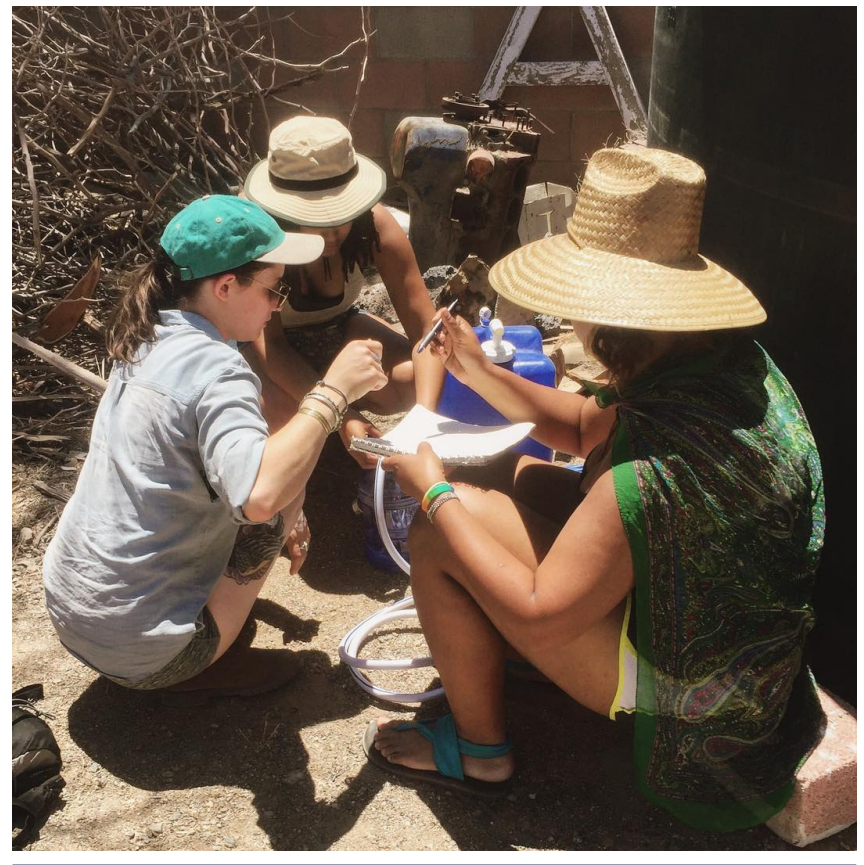

containers (Fig. 3). The water extraction was marked in a log book and signed off by the water receiver and the two water stewards (Fig. 4).

One of the challenges that emerged early on was the lack of grey water to flush the toilet (with flushing designated only for solid
Fig. 4. Log book of water distribution. Numbers (in gallons) show that when $<4$ gallons/day were used, the excess was "banked" for each person.

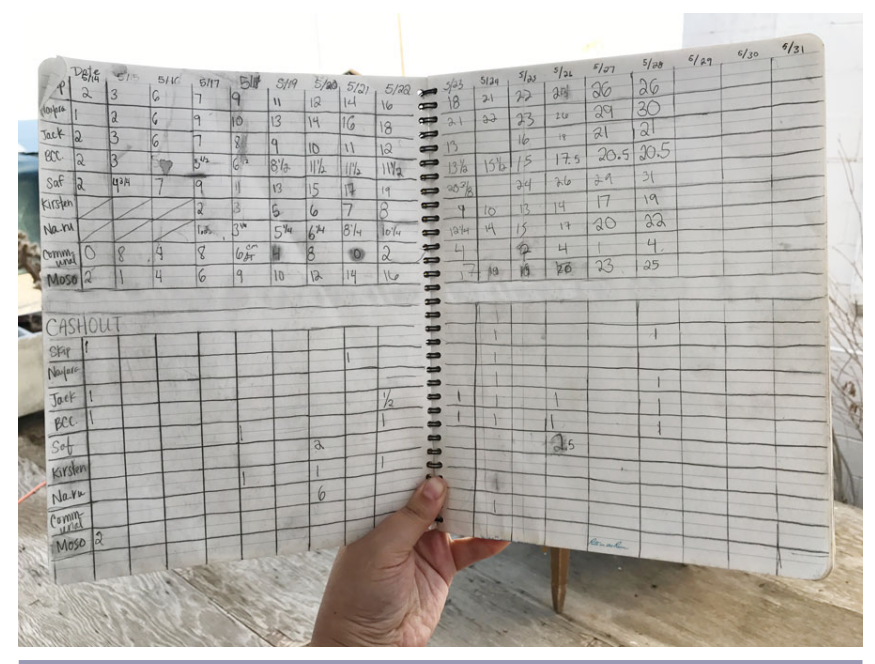

human waste, as we practiced "If it is yellow, let it mellow; if it is brown, flush it down"). During the first few days, we used the available salty water when needed and recorded this usage as if it were fresh water in our water allocation $\log$. After a number of days, we had produced more grey water from showering or washing our clothes; however, it was still not a sufficient supply to get rid of the waste. As a result, we decided to construct an outhouse with composting toilet. We collected recycled materials scattered around the compound to erect a functional and 
aesthetically pleasing outhouse halfway through the experiment. This resolved the shortage of grey water.

In Fig. 5, we show the weekly average water use per person per day. A remarkable outcome was that the $15.1 \mathrm{~L} /$ day of water was not a real constraint. We had organized ourselves in such a way that we used on average about 7.6 to $9.5 \mathrm{~L} /$ day of water per person. Our private water use stayed rather constant at $3.9 \mathrm{~L} /$ day of water, whereas the communal water use was lower in the last two weeks than in the first two weeks.

Fig. 5. Distribution of water use during each week of the experiment. Bars show the mean of the total amount of fresh water used (excluding grey water) per day per person.

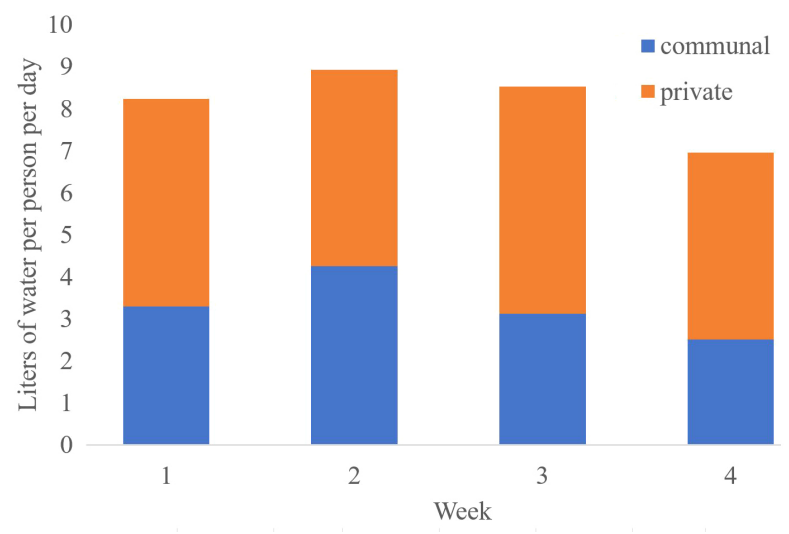

Another governance challenge was food preparation. A general lack of experience in cooking for larger groups, in particular, preparing diverse vegan meals, initially proved challenging. Ideally, lunch would consist of leftovers from the day before, but during the first week, we miscalculated and did not prepare enough food for everyone for both lunch and dinner. As such, a lot of time was spent preparing each meal. Over the weeks, we overcame those challenges.

Storage of food led to a number of collective action problems. We quickly became aware that we were not the only inhabitants of the compound and that rodents were eating food that was not stored properly. We began storing food in sealed containers, and cleaned and swept all surfaces at the end of each day. With one shared refrigerator among 12 people, we could not use it for personal needs such as keeping water cold. To solve this problem, we developed a system whereby we could produce a sufficient number of ice cubes during the day for making cold water.

As part of the project, we shared our experiences on a blog and disseminated the information via social media. The goal was to publish a group post each day and post an individual contribution to a personal blog every few days. We were free to express ourselves in whatever way we wished. Because the project created a fictional future scenario, some of us wrote blogs employing an element of suspense loosely based on activities in Amboy. We also used photographs, audio recordings, or video recordings to share our Drylab 2023 experience (see http://drylab2023.net/).

We designed the Drylab 2023 website and social media component to get the broader community involved and to enable the viewing public to pose questions that we would then answer. However, we experienced an additional resource dilemma. High-speed Internet service was not available in the rural area around Amboy, and most cellular phone services did not effectively transmit to the project site. The first day, we drove a few kilometers out of Amboy to connect with a cellular provider. However, using the hotspot in the way we were accustomed to at home, we went through 10 gigabytes in one evening (reaching the data limit). This was not a sustainable solution. We then purchased another hotspot option that could be received at the compound. However, we decided that only 20 gigabytes would be available for the rest of the project. This meant that the internet could only be used by designated laptops (with automated updates turned off) and only for projectrelated activities. Over the rest of the project, we successfully managed use of this limited resource and consumed only 14 gigabytes.

\section{RESULTING EFFECTS OF THE PROJECT}

The project affected the eight student participants in three ways: physical, social, and behavioral. Each experienced many physical impacts from the diet change, social impacts from being confronted with a situation of communalism, and behavioral impacts from the water restrictions. While the limited water situation was what everyone focused on, the hardest part of Drylab 2023 was living together and sharing the commons of space, Internet, and chores. Some of the most drastic physical impacts were observed by tracking our weight and our reactions to the diet throughout the project. At the end of our time together, $75 \%$ of us said we planned to change our diet after this project, and each one of us felt compelled to save grey water when we returned to our regular lives.

\section{Physical impacts}

The physical impacts from this project were less because of the water constraints and more because of the strict "water-wise" local vegan diet and lifestyle change (less stress, better sleep, more time in natural light, and a focus on hydration). After taking dairy, gluten, and animal products out of our diet, most of us felt less bloated, had more regular bowel movements, had fewer stomachaches, and felt like we had more energy overall despite the heat and limits to water. Everyone noticed that their body odor was different from eating vegan and unprocessed foods. One of our group recorded physical data during the project month, and all of us lost weight, with the average weight loss being 3.6 $\mathrm{kg}$ and the greatest weight loss being $5.4 \mathrm{~kg}$.

\section{Social impacts}

All of us struggled in some fashion with the social impacts. When we arrived on site, we found that almost none of us had mobile phone service. This caused some of us to feel isolated from our communities and families back home. Both the fact that the town had only four people and that bicycling too far out in the Mojave Desert could be dangerous because of extreme temperatures added to our sense of isolation. Bicycles were the only form of transportation everyone had access to, with only one shared car with a limited transportation budget. This meant that we spent a lot of time together: meals were cooked together, chores were shared, and grocery trips meant that several of us were packed in the car for the 3-h roundtrip drive. There was only one air conditioning unit that worked, so at first, all of us spent a large portion of each day together. As we acclimatized to the setting and settled into our new rhythms, we began to parse off into 
smaller groups. Nevertheless, many of us had a hard time being with so many people for so long, especially in a situation in which we were negotiating production of group meals and upkeep of a shared space. There was a struggle to learn to live together and adapt to communal thinking. For the first week and a half, there was a lot of tension, but then we started to get the hang of how to live together. However, by the last week, some of us started getting restless and agitated, perhaps because of the difficult circumstances of the $\geq 40^{\circ} \mathrm{C}$ heat.

We found that those of us who had certain skills in time and resource management, such as paying rent, allocating food and gas budgets, and so forth, were more successful at living on 15.1 L/day of water in the desert than people who did not have such experience. It was more difficult for those of us who had not previously had these sorts of responsibilities to adapt to conditions that required forethought, cooperation, and coordination.

\section{Behavioral impacts}

Each of us had the intention at the end of the project to be more water conscious and to start capturing grey water. Most of us had the intention of continuing the diet we ate at Drylab 2023. A month later, we compared notes to see how each of us were doing with our resolutions. All of us had newfound awareness of water usage and consciousness of our own consumption. Many of us had changed our behavior after Drylab 2023 such as adopting the "mellow-yellow" rule, saving grey water, and handwashing dishes. Those of us who were not as successful in changing our behavior around water consumption found that it was because of challenges related to sharing a space with other people that did not share our water consciousness. For example, those of us who shared a bathroom with other people faced objections to letting urine sit in the toilet ("mellow-yellow" rule). For these same reasons, as well as constraints on time and money, most of us did not keep up the water-wise diet.

Six of us used reusable sanitary products such as a "DivaCup," three of which had started using these products because of this project, saving a total of approximately 120 tampons each month. Overall, while our water usage and diet changes mostly went back to what they had been, we are now more conscious and aware of the consequences of our actions and try to mitigate them when possible.

\section{REFLECTION ON SELF-GOVERNANCE}

We next consider Ostrom's (1990) design principles to reflect on our experience of successful self-governance of our shared resources at Drylab 2023. Our successful performance is indicated by the observation that we used less water than the restricted allotment, less Internet bandwidth than allocated, and spent only USD \$7/day per person on food (our budget was \$10/day per person).

Design principle 1, well-defined boundaries: Our project was clearly defined as eight participants who committed themselves to a month-long experiment. However, our group included those of us who were not always present, but who followed the same regime when on the compound (i.e., faculty and staff). Other outsiders such as visitors did not follow the restricted use of resources, though it is important to note that residents and workers at
Amboy live every day with no access to running potable water. The water resource was clearly defined as a water tank.

The physical isolation and lack of Internet had important benefits. Because of the physical isolation of the site, there were no nearby temptations to violate the strict diet. During grocery shopping trips, temptations could be a challenge, and restraint and accountability were needed. The lack of access to the Internet encouraged us to interact with each other instead of with the rest of the world.

Design principle 2, proportional equivalent between benefits and costs: Why would people sign up for this experiment? Those of us who were recruited via an open call and personal networks perceived the experiment to be personally valuable and aligned with our emerging professional interests and commitments. The students received a modest stipend; course credits; and food, water, and lodging during our stay. Each of the students had defined plans to pursue activities during the stay in Amboy in the context of our research and artistic interests.

Design principle 3, collective choice arrangements: When we had group discussions, typically after dinner, every one of the eight students would have a say by passing around a "talking stick." We strived for unanimity, but when there was no obvious consensus, a vote was taken. Each of us was allocated one veto for the duration of the experiment so that we might exercise the power to reject a decision with which we strongly disagreed. No veto was used during the entirety of the project.

There were some challenges in collective decision making. Because there was no officially designated leader of our group, nor a chair during our collective meetings, some issues were left unresolved, but continued to be addressed further as needed. It is important to note that those of us who are faculty or staff only observed the collective decision making and let the others selforganize.

Design principle 4, monitoring: At the beginning of the project, water could only be dispensed from the water tank by the two water stewards. They recorded the water extraction in a log book, and both the receiver and the water stewards would sign off. After the first week, we discontinued the signatures. During the last week of the project, we instituted a new rule that allowed each participant to extract water as long as someone else was present, not necessarily one of the water stewards. The rationale was to make the process more flexible. Unfortunately, although this process continued the successful monitoring of water extraction, it resulted in incomplete recordings of water extraction in the log book.

Design principle 5, graduate sanctioning: We did not define consequences for the situation in which someone did not follow the agreed-upon procedures. As such, defined social norms existed, but firm rules did not (Ostrom 2005). This situation is not uncommon in small communities (De Moor et al. 2016). As long as informal processes work, no specific penalties are defined.

Design principle 6, conflict resolution: Prior to the project start, one of our group who had experience in conflict resolution was designated the point person for any necessary mediation. Upon seeing a need, the student members of our group gathered every 
few days to do a wellness and emotional check-in and openly express our feelings with each other.

Design principle 7, minimal recognition of rights: As is to be expected in any group, different people involved had different rights. Séverin Guelpa served as host and did not follow the selfimposed restrictions of the project during the two weeks he was at the compound. The same situation held for visitors (staying for less than one day). Those of us who were students were generally responsible to each other, whereas members who are faculty and staff did not participate in the formal decision making on how the group wanted to organize the limited resources. In certain cases, for example, in the context of excessive bandwidth use of the hotspot, those of us who are faculty set limits to stay within the project budget.

Design principle 8, nested enterprises: The project was located on a compound of a dilapidated motel behind locked gates. Interaction with the world outside the gate could be a challenge, given that people were unaware of the project. Going grocery shopping required restraint. We did engage with the few residents of Amboy. This led to some bartering of labor or handmade jewelry for some chocolate or other forbidden fruits.

This brief analysis of the design principles reveals that many of them were applicable to this experiment. However, there could have been improvements in collective choice arrangements and graduated sanctioning arrangements. Furthermore, monitoring became less strict over time. What explains our success was the development of bonds and trust relationships during the course of the project. Some of us indicated that we did not experience this experiment as a water governance exercise but as a process of living in harmony as a community undergoing scarcity and extreme conditions.

Although we were successful in meeting the project goals, our reliance on trust relationships might not have been sustainable if a serious conflict were to have emerged. Although there were challenges in living together, the unit remained functional until the end of the project. From historical analysis of the commons, we know that new institutional rules typically emerge after events occur that challenge the functioning of the community (De Moor 2015). For example, new rules of water management in the Republic of the United Netherlands were created in response to serious flooding events (Kaijser 2002). "One bad apple can spoil the bunch," meaning that if one person had chosen not to follow the social norms, that person could have created challenges to the initial Drylab 2023 institutional arrangements that would have been difficult to resolve. An evolution of collective choice arrangements and the instantiation of graduated sanctions and penalties might have been needed in such a situation. As an educational project, we are delighted to report that such events did not take place.

\section{REFLECTIONS BY PARTICIPANTS}

Here, we reflect on a number of themes that emerged during Drylab 2023 in discussions among the participants and with the followers on social media.

\section{Time}

Some of us expressed that we experienced a different perception of time. Temperatures and daylight defined what and when activities were done, not the official clock time. During the cooler morning hours, we participated in physical activities such as hiking or building the outhouse, whereas we rested during the hot afternoons. Being from a society that coordinates activities around clock time made this an enlightening experience for most of us. This aspect relates to the biggest challenge for many of us: the lack of Internet. With limited phone reception, most of us could not continue our online habits as we were used to do. Although this was a challenge, toward the end of the project, many of us reported being grateful for the time spent away from our screens. This time may have facilitated the rich group dynamic and commitment to the project.

\section{Structure vs. lack of structure}

Less than halfway through the project, some of us expressed concerns about shared responsibility regarding upkeep of the house. We decided to eschew a firm structure of rotating chores because a portion of us expressed an antipathy for structured time (cleaning schedules, etc.). Instead, we worked together to address the need for cleanliness and order (which must be said, varied greatly among us) through novel ways of organizing the space. It came to light that those of us who identified as scientists and social scientists were invested in and more comfortable with structured time schedules, whereas those of us who identified as artists enjoyed and yearned for greater structuring of space. We learned that the issue was not one of liking or disliking structure (as it was originally posed), but rather could be understood around structured time vs. structured space. It should be noted that other variables such as age, experience, and previous independent living (with the majority of the artists being older and having lived on their own for a longer time) may have affected this split more than a cultural distinction between artists and scientists. Nevertheless, this insight could be explored further, especially because we continue to have interest in further crossdisciplinary art and science collaborations.

\section{Speculative fiction frame}

During the project, the near future speculative fiction scenario became closer to fact. We developed the basic storyline in the early fall semester, and then the election of U.S. President Donald Trump made our storyline more realistic. This was illustrated by the United States' withdrawal from the Paris Climate agreement during our stay in Amboy (we blogged about this from the perspective of the sixth year anniversary), as well as the return to viability of a proposed groundwater extraction project in the Mojave Desert by the private company Cadiz (Jablon 2017) and the rapid dismantling of U.S. Environmental Protection Agency regulations.

Some of us felt comfortable with and shielded by the fictional framework, using our characters to dramatize important perspectives and struggles. Other group members chafed under the performative framework and cast it aside, merging our identity with our character and relaxing into life as it unfolded.

\section{Privilege}

The issue of privilege loomed large for us. Some followers of our blog posts raised the issue that our group consisted of privileged people who can go back to a resourceful society at the end of the 30 days, whereas many others live this life in reality. In response, we held serious and significant discussions about this issue, eventually resulting in an important response posted to the Drylab 
2023 website. To summarize the posted response, we articulated that this project was meant to raise awareness of issues of water scarcity, already a reality for many people in the United States and beyond. The project was an educational experience, not a solution to a problem. The project demonstrates that living in such resource-scarce environments can be a doable and pleasant experience. We stated the following.

\begin{abstract}
The more money you have, the more water you use; there is a direct correlation between wealth and water use. If we are the ones using the most resources, then we are the ones who need to learn how to use less. If privileged people won't change their water usage, then inequalities won't change. Drylab is a simulation of the work that privileged folks ought to be doing: experiencing water scarcity and sustainable living, phenomena which we are currently free to dismiss. We also hope to bring this information not to people who already live in scarcity, but to other privileged people who are wasteful with their water and have never had to experience scarcity or consider the ramifications of their overconsumption. We hope to use our privilege and platform that we have created to bring awareness to these issues. Source: http://drylab2023.net/.
\end{abstract}

\section{Individualism}

In addressing the problems we experienced, solutions were proposed in line with what we were used to doing. Because all of us grew up in North America, private property is a default allocation of resources. This reflects observed differences in cultural upbringing and how they shape thinking and actions related to the commons. Nisbett (2003) demonstrates the difference in thinking between the individualistic Westerns and the collective Asians.

This factor also explains why, on the first day, we immediately moved the original design from $7.55 \mathrm{~L} /$ day of personal water and $7.55 \mathrm{~L} /$ day of communal water to $11.35 \mathrm{~L} /$ day personal and 3.8 $\mathrm{L} /$ day communal water, reverting to the private property model. This caused a shortage of communal water, leaving us a few days when we ran out of communal water. When one of us requested to move back to the original design (50:50), many of us resisted. The final vote was a tie, and the idea was put aside. After it was calculated in week 3 that we would have access to more water if we moved to the original structure, there was still some hesitancy, although we reported that this was related to the difficulty of making a change so late in the project.

\section{Cultural challenges between artists and scientists}

Aside from the differences in relation to time and space, there were some marked cultural differences that were attributed to being trained in art vs. science. Those of us who were trained in science wanted charts, rules, structure, and discipline; had a hard time with free time; and struggled with self-structured time and abstraction. Those of us who are trained as artists had a different way of doing things than the scientists and vice versa. One example is that the artists wanted the final presentation to the community to be a picture slideshow, whereas the scientists yearned for a chance to interpret their data and show their results. For the artists, the final presentation as images had to do with thinking about the relationship between the group as authors, presenters, and artists and the audience, a key critical demand when creating aesthetic experiences. However, those that were interested in working across disciplines were able to work together by being mindful of their behavior, willing to compromise, flexible, and adaptable.

\section{DISCUSSION}

In a recent special feature in Ecology and Society titled Reconciling Art and Science for Sustainability, the collaboration between artists and scientists was stimulated because it could provide the generation of original ideas and reflections on the science that scientists are doing (Scheffer et al. 2017). Staying in an extreme environment for a number of weeks with immersive experiences of resource scarcity and plenty of unstructured space enabled us to reflect on various sustainability and project-related issues. We close with a discussion on how this experience might be relevant for readers of Ecology and Society.

Since the art and sustainability project allowed us to do experimentation that would not be possible in a scientific experiment, author Janssen was able to observe the emergence of institutional arrangements in the group. Despite the unique situation, the institutions crafted follow very well most of the insights from Ostrom's (1990) design principles. As a self-selected group, we were able to share our limited resources for the duration of the project and crafted institutional arrangements that fit within the specific context. However, some design principles such as conflict resolution and graduated sanctioning were not met, which is in line with historical studies and indicates a potential lack of resilience for the group. This experience confirms that we need to develop a more dynamic understanding of the design principles instead of a static list.

When this project was launched, most outsiders perceived this as a kind of survival project. In practice, we did not experience the water constraints as a limiting physical factor because we successfully adjusted our everyday lifestyle and coordinated effectively with each other to negotiate within scarcity. Although we know that people can change their lifestyle, it was a surprise for us that a transition to a reduction of water consumption by $95 \%$ was not a major challenge, at least for the duration of the project. No new technologies were needed to live with water scarcity because behavioral changes were sufficient. The transition might largely be shaped by the distant physical location and unique site where we were living. The biophysical environment restricted temptations to high-resource lifestyles, which supported our persistence in this temporary lifestyle change. The lifestyle changes were difficult to maintain when we returned from the isolated environment.

Drylab 2023 was a unique and extreme experience, suggesting that it would be worthwhile to consider replications of art and sustainability projects to explore more systematic behavioral changes and institutional innovations in extreme environments. Possible replications could be performed in dedicated student dorms where residents commit to long-term art and sustainability projects to simulate possible futures and extreme adaptations. Such campus-based simulations could also allow for better opportunities for performing scientific research and monitoring behavioral changes. The artistic perspective will still be essential to provide a narrative and meaning to the participants in these extreme adaptations.

To conclude, our art and sustainability project responded to the challenge of bringing science and art together to explore 
unexplored spaces. The project underscored the lack of understanding we have in the evolution of institutions, but allowed us to experience the power of (temporal) behavioral change. The increasing use of such projects may provide better insights into needed behavioral changes in Western societies toward a more sustainable society.

Responses to this article can be read online at: http://www.ecologyandsociety.org/issues/responses. php/10299

\section{Acknowledgments:}

We thank the School of Art and the School of Sustainability at Arizona State University, and the Foundation for Scientific Symbiosis for financial support. We also thank the residents of Amboy for their involvement.

\section{LITERATURE CITED}

Bakker, K. 2010. Privatizing water: governance failure and the world's urban water crisis. Cornell University Press, Ithaca, New York, USA. http://dx.doi.org/10.7591/9780801463617

City of Cape Town. 2018. Water outlook 2018 report, revision 25. Department of Water and Sanitation, City of Cape Town, Cape Town, South Africa. [online] URL: https://resource.capetown. gov.za/documentcentre/Documents/City

$\% 20$ research $\% 20$ reports $\% 20$ and $\% 20$ review/Water $\% 20$ Outlook $\%$ 202018\%20-\%20Summary.pdf

Cook, B. I., T. R. Ault, and J. E. Smerdon. 2015. Unprecedented 21 st century drought risk in the American Southwest and Central Plains. Science Advances 1(1):e1400082. http://dx.doi.org/10.1126/ sciadv. 1400082

De Moor, T. 2015. The dilemma of the commoners: understanding the use of common-pool resources in long-term perspective. Cambridge University Press, Cambridge, UK. https://doi. org/10.1017/CBO9781139135450

De Moor, T., M. Laborda-Pemán, J. M. Lana-Berasain, R. van Weeren, and A. Winchester. 2016. Ruling the commons. Introducing a new methodology for the analysis of historical commons. International Journal of the Commons 10(2):529-588. https://www.thecommonsjournal.org/articles/10.18352/ijc.760/

Elliott, J., D. Deryng, C. Müller, K. Frieler, M. Konzmann, D. Gerten, M. Glotter, M. Flörke, Y. Wada, N. Best, S. Eisner, B. M. Fekete, C. Folberth, I. Foster, S. N. Gosling, I. Haddeland, N. Khabarov, F. Ludwig, Y. Masaki, S. Olin, C. Rosenzweig, A. C. Ruane, Y. Satoh, E. Schmid, T. Stacke, Q. Tang, and D. Wisser. 2014. Constraints and potentials of future irrigation water availability on agricultural production under climate change. Procedings of the National Academy of Sciences 111 (9):3239-3244. http://dx.doi.org/10.1073/pnas.1222474110

Genovés, S. 1975. The Acali experiment: five men and six women on a raft across the Atlantic for 101 days. Times Books, New York, New York, USA.
Gleick, P. H. 1996. Basic water requirements for human activities: meeting basic needs. Water International 21(2):83-92. http://dx. doi.org/10.1080/02508069608686494

Hoekstra, A. Y., and A. K. Chapagain. 2007. Water footprints of nations: water use by people as a function of their consumption pattern. Water Resources Management 21(1):35-48. http://dx.doi. org/10.1007/s11269-006-9039-X

Jablon, R. 2017. Mojave Desert water project gets Trump Administration boost. Cadiz, Los Angeles, California, USA. [online] URL: http://cadizinc.com/2017/04/05/mojave-desertwater-project-gets-trump-administration-boost/

Kaijser, A. 2002. System building from below: institutional change in Dutch water control systems. Technology and Culture 43(3):521-548. http://dx.doi.org/10.1353/tech.2002.0120

Konikow, L. F. 2013. Groundwater depletion in the United States (1900-2008). Scientific Investigations Report 2013-5079. U.S. Geological Survey, Reston, Virginia, USA. https://doi. org/10.3133/sir20135079

Konikow, L. F., and E. Kendy. 2005. Groundwater depletion: a global problem. Hydrogeology Journal 13(1):317-320. http://dx. doi.org/10.1007/s10040-004-0411-8

Mack, E. A., and S. Wrase. 2017. A burgeoning crisis? A nationwide assessment of the geography of water affordability in the United States. Plos One 12(1):e0169488. https://doi. org/10.1371/journal.pone.0169488

Mekonnen, M. M., and A. Y. Hoekstra 2011. The green, blue and grey water footprint of crops and derived crop products. Hydrology and Earth System Sciences 15(5):1577-1600. https:// doi.org/10.5194/hess-15-1577-2011

Nisbett, R. E. 2003. The geography of thought: how Asians and Westerners think differently... and why. Free Press, New York, New York, USA.

Ostrom, E. 1990. Governing the commons: the evolution of institutions for collective action. Cambridge University Press, Cambridge, UK.

Ostrom, E. 2005. Understanding institutional diversity. Princeton University Press, Princeton, New Jersey, USA.

Ostrom, E. 2010. Beyond markets and states: polycentric governance of complex economic systems. American Economic Review 100(3):641-672. http://dx.doi.org/10.1257/aer.100.3.641

Poteete, A. R., M. A. Janssen, and E. Ostrom. 2010. Working together: collective action, the commons, and multiple methods in practice. Princeton University Press, Princeton, New Jersey, USA.

Reider, R. 2010. Dreaming the biosphere: the theater of all possibilities. University of New Mexico Press, Albuquerque, New Mexico, USA.

Scheffer, M., M. Baas, and T. K. Bjordam. 2017. Teaching originality? Common habits behind creative production in science and arts. Ecology and Society 22(2):29. http://dx.doi.org/10.5751/ ES-09258-220229 
Scheffer, M., J. Bascompte, T. K. Bjordam, S. R. Carpenter, L. B. Clarke, C. Folke, P. Marquet, N. Mazzeo, M. Meerhoff, O. Sala, and F. R. Westley. 2015. Dual thinking for scientists. Ecology and Society 20(2):3. http://dx.doi.org/10.5751/ES-07434-200203

Smith, J. F. 2010. Life under the bubble. Discover 20 December 2010. [online] URL: http://discovermagazine.com/2010/oct/20life-under-the-bubble

Vörösmarty, C. J., P. Green, J. Salisbury, and R. B. Lammers. 2000. Global water resources: vulnerability from climate change and population growth. Science 289:284-288. http://dx.doi.org/10.1126/ science.289.5477.284 